\title{
Perspective Series: Nitric Oxide and Nitric Oxide Synthases
}

\section{Cellular and Molecular Mechanisms of Endothelial Cell Dysfunction}

\author{
David G. Harrison \\ Emory University Cardiology Division, Department of Internal Medicine and the Atlanta Veterans Administration Medical Center, \\ Atlanta, Georgia 30322
}

\begin{abstract}
Introduction
The clinical relevance of the vascular L-arginine/nitric oxide $(\mathrm{NO})^{1}$ synthase system to vascular biology lies in the oftrepeated observation that it is altered by a variety of pathophysiological conditions. Such alterations of NO production and/or bioavailability have been shown to occur both in experimental animal models and in human subjects, in the setting of such diverse disorders as hypertension, hypercholesterolemia, aging, cigarette smoking, diabetes, and heart failure (1). The mechanisms underlying the alteration of this important function of the endothelium are varied and likely multifactorial. During the past several years an enormous amount of research has been devoted to understanding these abnormalities, which has led to new insights into regulation of vascular tone, redox state, inflammation, growth, and the prothrombotic/antithrombotic properties of the vessel wall. This Perspective will highlight some of these important new observations, as they relate to the pathology of the endothelial cell $\mathrm{L}$-arginine/NO synthase (NOS) system. In addition, future directions of research that may be particularly informative will be indicated.
\end{abstract}

\section{Alterations of the substrate for the NOS enzyme}

The substrate for NOS is the basic amino acid L-arginine (with a $K_{\mathrm{m}}$ of approximately $5 \mu \mathrm{M}$, reference 2 ). L-Arginine is synthesized as a product of the urea cycle and circulates in the blood in concentrations of $\sim 100 \mu \mathrm{M}$ (3). In endothelial cells, however, the concentration of L-arginine has been estimated to be several hundred to several thousand micromolars $(4,5)$. L-Arginine is actively transported into the endothelium by a $\mathrm{y}+$ transporter, and this process is subject to regulation by cytokines (6-9). Even in the absence of extracellular L-arginine, the endothelium can resynthesize this amino acid from L-citrulline using a recently described novel biosynthetic pathway (5).

Given the fact that the intracellular levels of L-arginine far exceed the $K_{\mathrm{m}}$ of the NOS enzyme, it appears unlikely that administration of the enzyme affects cellular NO production. In-

Address correspondence to David G. Harrison, Division of Cardiology, Emory University School of Medicine, 1639 Pierce Drive, 319 WMB, Atlanta, GA 30322. Phone: 404-727-3710; FAX: 404-727-3330; E-mail: dharr02@emory.edu

Received for publication 1 October 1997.

1. Abbreviations used in this paper: ADMA, asymmetric dimethyl arginine; NO, nitric oxide; NOS, NO synthase.

J. Clin. Invest.

(C) The American Society for Clinical Investigation, Inc. 0021-9738/97/11/2153/05 \$2.00

Volume 100, Number 9, November 1997, 2153-2157

http://www.jci.org deed, in isolated organ chambers, we have found that L-arginine has no effect on endothelium-dependent vascular relaxations of aortas from normal and cholesterol-fed rabbits (10). However, numerous other studies have demonstrated beneficial effects of L-arginine on vascular responses in vivo, both in experimental animals and in humans in several conditions, including hypercholesterolemia, hypertension, and diabetes (11-16). Even oral feeding of L-arginine, which only doubles plasma levels, appears to have beneficial effects not only on vasomotion, but also on atherosclerosis development in cholesterol-fed rabbits as well as on hypertension in rats $(16,17)$.

The mechanisms by which L-arginine exerts these effects are unclear. Infusions of the amino acid may produce effects independent of its role as a substrate for NOS, such as by stimulating insulin release or acting as a direct vasodilator (18). One potential explanation for the beneficial effect of L-arginine is that it may overcome the effect of endogenous antagonists of NOS, such as asymmetric dimethyl arginine (ADMA). ADMA has been shown to accumulate in the plasma of cholesterol-fed rabbits, in humans with renal failure, and in elderly subjects with peripheral vascular disease $(3,19)$. However, the plasma levels of ADMA in these conditions are $\sim 3 \mu \mathrm{M}$ (only a fraction of the plasma L-arginine levels) and therefore unlikely to antagonize L-arginine as substrate for $\operatorname{NOS}(3,19)$. Nevertheless, the intracellular levels of ADMA in these conditions are not known, and it is thus conceivable that they are higher than plasma levels and that disordered synthesis of L-arginine and ADMA might impact the cellular production of NO. Future studies of L-arginine and ADMA cellular metabolism in various disease states should be very informative.

Another consideration regarding the modulation of L-arginine levels in the endothelium is the presence of the enzyme arginase, which can convert arginine to ornithine and urea. Arginase I is constitutively present in endothelial cells, while the so-called "extrahepatic" form, arginase II, can be induced in endothelial cells by lipopolysaccharide and $\gamma$-interferon (20). Interestingly, arginase activity is inhibited by $N$-hydroxyarginine, the intermediate of the NOS pathway (20). Therefore, induction of arginase could limit L-arginine as a substrate for NOS, and may be important in modulating cellular NO production. Future experiments are clearly needed to examine arginase expression and activity in various disease states where NO production and/or bioactivity is altered.

Overall, existing data strongly suggest that arginine supplementation can modulate in vivo NO production, but the mechanisms are far from clear. Additional work is needed to understand if this is a direct or indirect effect. It is possible that the concentration of L-arginine in microdomains of the cell (e.g., in the caveolae) is not reflected in the total cellular concentration. It is also possible that the rate of transport of L-arginine into these regions may be more critical than the absolute cellular concentrations. 


\section{Alterations of NOS expression/structure}

Another factor that may affect endothelial NO production in various pathophysiological conditions is the level of expression of the eNOS enzyme. Although eNOS is constitutively expressed, both in vivo and in vitro studies have made it clear that its expression is subject to modest (but likely important) degrees of regulation. In cultured cells, eNOS expression is increased by shear stress (21), cyclic strain (22), exposure to lysophosphatidylcholine (23), low concentrations of oxidized low density lipoprotein (24), and cyclic GMP analogues (25). In vivo, it has been demonstrated that exercise training in dogs increases eNOS expression and the ability of blood vessels to dilate in response to agonists that release endogenous NO $\left(\mathrm{NO}^{\bullet}\right)(26)$

Several potential pathophysiological factors have been shown to lower eNOS expression. Exposure of cultured endothelial cells to TNF- $\alpha$, hypoxia, and high concentrations of oxidized low density lipoprotein decrease eNOS levels (for review see reference 27). Under these conditions, posttranscriptional changes in mRNA half-life play an important role in the downregulation of eNOS expression. For example, the expression of eNOS is markedly reduced in endothelial cells overlying advanced atherosclerotic lesions (28). Obviously, such a loss in eNOS expression would have a significant impact on endothelial regulation of vasomotion.

Recently, a polymorphism of the human eNOS gene has been identified that appeared to be linked to hypertension in the Japanese (29), although such a linkage was not observed in another population (30). Therefore, whether or not changes in eNOS expression and or function occur as a result of such polymorphisms remains controversial and needs further study. Furthermore, studies linking physiological measurements to genetic analyses would provide important additional information.

\section{Alterations of NO signaling}

A factor that is likely altered by various disease states is the way in which the NOS enzyme is activated. Endotheliumdependent vasodilation in response to the calcium ionophore A23187 is, in general, not altered to as great an extent as are responses to receptor-mediated stimuli (31). Because calcium ionophores elicit NO release by promoting calcium influx into the endothelium independent of receptor activation, this suggests that there is a defect in either the membrane receptors or the signaling mechanisms activated by these receptors. There has been substantial interest in alterations of $\mathrm{G}$ protein coupling and/or expression in various diseases (32). It is known that the acute administration of pertussis toxin alters endothelium-dependent vascular relaxation to some, but not all, agonists. Cholesterol feeding of pigs produces a defect in endothelium-dependent vascular relaxation that resembles the defect produced by pertussis toxin (32). One explanation for these alterations of $G$ protein signaling is related to changes in membrane fluidity, which could prevent the interactions of the $\mathrm{G}$ proteins with the receptors responsible for eNOS activation. In tissue culture, expression of Gai2 is inhibited by oxidized LDL (33). In human coronary arteries, $\mathrm{G}_{\mathrm{i} a}$ expression is impaired by age, hypertension, and hypercholesterolemia (34). Such a defect could explain how these various diseases alter endothelium-dependent vasodilation in response to a variety of receptor-dependent agonists.

Understanding alterations of eNOS signaling is currently hampered because the mechanisms by which the eNOS is activated in the endothelial cell are still incompletely understood. It is clearly more complex than simple interactions between eNOS and calcium/calmodulin. Movement of the enzyme in and out of the caveolae and association with caveolin are probably important, as discussed by Thomas Michel and Olivier Feron in the accompanying Perspective (see reference 37). Likewise, the state of phosphorylation of the eNOS protein may be important (35).

More work aimed at understanding eNOS signaling and how it is altered by various disease processes is clearly required. This should include studies of the $G$ proteins involved in eNOS signaling (different agonists versus shear), other possible signaling functions (e.g., phosphorylation and subcellular movement of eNOS), any inhibitory factors as they relate to eNOS function (e.g., anionic phospholipids [36], caveolin [37], and other molecules), and how all of these can be altered by diseases.

\section{Alteration of tetrahydrobiopterin availability}

Tetrahydrobiopterin is a critical cofactor for the NOSs and appears to contribute to the ability of the enzymes to bind L-arginine. Interestingly, in the absence of tetrahydrobiopterin, the enzyme transfers electrons to molecular oxygen to produce the superoxide anion (38). Mammalian cells generate tetrahydrobiopterin via the activity of the enzyme GTP cyclohydrolase I. One important property of tetrahydrobiopterin is that it is very redox-active, and is capable of both generating and scavenging oxygen radicals (39). Although levels of tetrahydrobiopterin have not been measured in the endothelium in various pathophysiological states, recent physiological studies suggest that it may be deficient in conditions like diabetes and hypercholesterolemia $(40,41)$. These are very provocative findings, but it is conceivable that the tetrahydrobiopterin is simply acting as an antioxidant under such conditions. Future work to examine the manner in which various disease states affect tetrahydrobiopterin biosynthesis, insertion of tetrahydrobiopterin into NOS, and oxidative modification of tetrahydrobiopterin are clearly warranted.

\section{Destruction of NO by reactive oxygen species}

Both superoxide and NO are free radicals (i.e., they contain an unpaired electron in their outer orbital). When exposed to each other, they undergo a facile radical-radical reaction that proceeds at a rate recently estimated to be $6.7 \times 10^{9} \mathrm{M}^{-1} / \mathrm{s}^{-1}$ (42). This is approximately three times faster than the reaction rate for superoxide with either the manganese or copper/zinc SODs. Thus, in a compartment in which both NO and SOD exist, there may be a propensity for superoxide to preferentially react with NO rather than SOD, depending on the relative concentrations of NO and SOD present.

Evidence from both experimental animals and humans suggests that oxidative inactivation of NO may also be important in various pathological conditions. For example, large amounts of nitrogen oxides are released from vessels in an oxidatively degraded state in cholesterol-fed rabbits (43). Treatment of these rabbits with polyethylene-glycolated SOD dramatically increased endothelium-dependent vascular relaxation, further suggesting a role for superoxide (44). Vascular superoxide production in cholesterol-fed rabbits appeared to be from xanthine oxidase, because production was inhibited by oxypur- 
inol. More recently, it has been shown that levels of xanthine oxidase are increased in the plasma of cholesterol-fed rabbits, and that this circulating xanthine oxidase binds to heparinbinding sites on the vessel, where it acts to produce excess superoxide (45). There is also evidence that reactive oxygen species also diminish NO bioactivity in humans. For example, infusion of ascorbic acid improves vascular responses to acetylcholine in cigarette smokers, diabetic individuals, and in hypertension (46-48).

\section{The vascular NADH/NADPH oxidase as a major source of superoxide}

One of the most exciting developments in vascular biology in the last few years is the observation that both the endothelium and vascular smooth muscle contain membrane-bound oxidases that use NADH and NADPH as substrates for electron transfer to molecular oxygen (49-52). These recently discovered oxidases are similar to the neutrophil NADPH oxidase $(53,54)$ in that they possess flavin- and heme-binding regions that are likely important in the transfer of electrons. They also share at least one protein subunit, p22phox (see below). However, there are also important differences between the vascular and the neutrophil oxidases. First, the output of the vascular oxidase is much lower than that of the neutrophil oxidase (nmol vs. $\mu \mathrm{mol} / \mathrm{min} / \mathrm{mg}$ protein). Second, the vascular oxidase does not exhibit "bursts" of activity, as does the neutrophil form $(55,56)$. However, this low-output property does not detract from the importance of the vascular oxidase system. The neutrophil oxidase system plays a bactericidal role, while the vascular oxidase probably fulfills other roles, such as the modulation of NO activity. Finally, unlike the neutrophil oxidase, the smooth muscle oxidase uses NADH in preference to NADPH.

One particularly important aspect of the vascular NADH/ NADPH oxidases is that their activity is regulated by angiotensin II (49), as well as by several cytokines. Studies have shown that a 4-h treatment of cultured vascular smooth muscle cells with nanomolar levels of angiotensin II markedly increases NADH and NADPH oxidase activity. Recent studies have extended these findings to an in vivo model of angiotensin II-induced hypertension (57). Vessels from rats made hypertensive by chronic (i.e., 5-d) infusions of angiotensin II produce increased amounts of superoxide, show increased NADH/NADPH oxidase activity, and have abnormal endothelium-dependent vasodilation. Furthermore, the abnormal endothelium-dependent vasodilation can be improved with a cell-targeted form of SOD. These abnormalities of vascular function are not present in rats made hypertensive by chronic infusion of norepinephrine, suggesting that hypertension alone is not responsible for activation of the oxidase. This conclusion was supported by additional experiments in which low concentrations of angiotensin II were infused, resulting in only a small $(10 \mathrm{mmHg})$ increase in blood pressure. In these animals, a perturbation of vascular superoxide production was observed, similar to that observed in rats made overtly hypertensive by angiotensin II infusion. This perturbation probably extends to the resistance circulation, because treatment of rats with liposome-entrapped SOD ameliorates angiotensin II-induced hypertension (58).

Interestingly, chronic nitroglycerin therapy is also associated with an increase in vascular NADH/NADPH oxidase activity and total vascular superoxide production (55). Treatment of vessels with liposome-entrapped SOD corrected the nitro- glycerin tolerance, suggesting that activation of oxidases may be important in this clinical entity (59).

As discussed above, an important component of the vascular smooth muscle NADH/NADPH oxidase is p22phox, the small protein subunit of the membrane oxidase cytochrome (60). Stable transfection of vascular smooth muscle cells with a full-length p22phox antisense transgene results in a marked decrease in the capacity of these cells to produce superoxide in response to angiotensin II (61). Furthermore, the vascular expression of $\mathrm{p} 22 \mathrm{phox}$ is dramatically increased during angiotensin II infusion, and the time courses of p22phox expression, NADH/NADPH oxidase activity, and the development of hypertension parallel each other (62). Taken together, these data strongly support a role of $\mathrm{p} 22 \mathrm{phox}$ in control of vascular superoxide production and its modulation by angiotensin and hypertension. Interventions to modify vascular p22phox expression and/or function could prove to be very helpful in modulating production of reactive oxygen species and the bioactivity of endothelium-derived NO. Future studies to examine other components of the vascular oxidase system and their roles in various disease states should be extremely informative. Likewise, studies examining other sources of reactive oxygen species in vascular tissues and how they are modulated will be helpful in understanding regulation of NO bioactivity. Finally, studies of regulation of the major antioxidant defense systems (i.e., the SODs, cellular thiols, and antioxidant vitamins) will likely provide additional insight into how various diseases affect the NOS system.

\section{Conclusion}

In this Perspective, I have discussed multiple potential causes for alterations of vascular NO release and/or bioactivity. Although the diseases that are associated with impaired NO function are diverse, it is interesting to note that the ultimate effect on endothelial NO production is similar, and that this may be because of similar underlying causes. The "read-out" in most of these studies has been an impairment in endotheliumdependent vasodilation, but it is clear that NO has a number of other important functions in the vessel wall, such as inhibition of platelet aggregation and of adhesion molecule expression, prevention of smooth muscle proliferation, and modulation of vascular growth. Thus, NO influences vascular homeostasis in many ways beyond simple modulation of vasomotion. In fact, NO may be considered an antiatherogenic, antiproliferative, and antithrombotic factor. Because of this, the loss of NO production and bioactivity could explain why diverse pathological conditions such as hypercholesterolemia, hypertension, diabetes, and cigarette smoking are all considered risk factors for atherosclerosis. Further studies of endothelial cell NO production, NOS expression, cofactor availability, and NO degradation will, undoubtedly, provide greater understanding of how these various disorders modulate vasomotion and predispose to vascular disease.

\section{References}

1. Harrison, D.G. 1996. Endothelial control of vasomotion and nitric oxide production. Cardiol. Clin. 14:1-15.

2. Venema, R., H. Sayegh, J. Kent, and D. Harrison. 1996. Identification, characterization, and comparison of the calmodulin-binding domains of the endothelial cell and inducible nitric oxide synthases. J. Biol. Chem. 271:6435-6440.

3. Boger, R.H., S.M. Bode-Boger, W. Thiele, W. Junker, K. Alexander, and J.C. Frolich. 1997. Biochemical evidence for impaired nitric oxide synthesis in patients with peripheral arterial occlusive disease. Circulation. 95:2068-2074. 
4. Arnal, J.-F., T. Münzel, R.C. Venema, N.L. James, C.-L. Bai, W.E. Mitch, and D.G. Harrison. 1995. Interactions between L-arginine and L-glutamine change endothelial NO production. An effect independent of NO synthase substrate availability. J. Clin. Invest. 95:2565-2572.

5. Hecker, M., W.C. Sessa, H.J. Harris, E.E. Ånggard, and J.R. Vane. 1990. The metabolism of L-arginine and its significance for the biosynthesis of endothelium-derived relaxing factor: cultured endothelial cells recycle L-citrulline to L-arginine. Proc. Natl. Acad. Sci. USA. 87:8612-8616.

6. Bogle, R.G., A.R. Baydoun, J.D. Pearson, and G.E. Mann. 1996. Regulation of L-arginine transport and nitric oxide release in superfused porcine aortic endothelial cells. J. Physiol. 490:229-241.

7. Cendan, J.C., W.W. Souba, E.M.R. Copeland, and D.S. Lind. 1995. Cytokines regulate endotoxin stimulation of endothelial cell arginine transport. Surgery (St. Louis). 117:213-219.

8. Durante, W., L. Liao, K. Cheng, and A.I. Schafer. 1996. Selective induction of a cationic amino acid transporter by tumor necrosis factor-alpha in vascular endothelium. Proc. Assoc. Am. Phys. 108:356-361.

9. Sobrevia, L., A. Nadal, D.L. Yudilevich, and G.E. Mann. 1996. Activation of L-arginine transport (system $\mathrm{y}+$ ) and nitric oxide synthase by elevated glucose and insulin in human endothelial cells. J. Physiol. 490:775-781.

10. Mügge, A., and D.G. Harrison. 1991. L-arginine does not restore endothelial dysfunction in atherosclerotic rabbit aorta in vitro. Blood Vessels. 28:354 357.

11. Cooke, J.P., N.A. Andon, X.J. Girerd, A.T. Hirsch, and M.A. Creager. 1991. Arginine restores cholinergic relaxation of hypercholesterolemic rabbit thoracic aorta. Circulation. 83:1057-1062.

12. Creager, M.A., S.J. Gallagher, X.J. Girerd, S.M. Coleman, V.J. Dzau, and J.P. Cooke. 1992. L-Arginine improves endothelium-dependent vasodilation in hypercholesterolemic humans. J. Clin. Invest. 90:1248-1253.

13. Drexler, H., A.M. Zeiher, K. Meinzer, and H. Just. 1991. Correction of endothelial dysfunction in coronary microcirculation of hypercholesterolaemic patients by L-arginine. Lancet. 338:1546-1550.

14. Girerd, X.J., A.T. Hirsch, J.P. Cooke, V.J. Dzau, and M.A. Creager. 1990. L-arginine augments endothelium-dependent vasodilation in cholesterolfed rabbits. Circ. Res. 67:1301-1308.

15. Pieper, G.M., and B.A. Peltier. 1995. Amelioration by L-arginine of a dysfunctional arginine/nitric oxide pathway in diabetic endothelium. J. Cardiovasc. Pharmacol. 25:397-403.

16. Chen, P.Y., and P.W. Sanders. 1993. Role of nitric oxide synthesis in salt-sensitive hypertension in Dahl/Rapp rats. Hypertension (Dallas). 22:812-818.

17. Cooke, J.P., A.H. Singer, P. Tsao, P. Zera, R.A. Rowan, and M.E. Billingham. 1992. Antiatherogenic effects of L-arginine in the hypercholesterolemic rabbit. J. Clin. Invest. 90:1168-1172.

18. Guigliano, D., R. Marfella, G. Verrazzo, R. Acampora, L. Coppola, D. Cozzolino, and F. D'Onofrio. 1997. The vascular effects of L-arginine in humans. The role of endogenous insulin. J. Clin. Invest. 99:433-438.

19. Vallance, P., A. Leone, A. Calver, J. Collier, and S. Moncada. 1992. Accumulation of an endogenous inhibitor of nitric oxide synthesis in chronic renal failure. Lancet. 339:572-575.

20. Buga, G.M., R. Singh, S. Pervin, N.E. Rogers, D.A. Schmitz, C.P. Jenkinson, S.D. Cederbaum, and L.J. Ignarro. 1996. Arginase activity in endothelial cells: inhibition by $N^{\mathrm{G}}$-hydroxy-L-arginine during high-output $\mathrm{NO}$ production. Am. J. Physiol. 271:H1988-H1998.

21. Nishida, K., D.G. Harrison, J.P. Navas, A.A. Fisher, S.P. Dockery, M. Uematsu, R.M. Nerem, R.W. Alexander, and T.J. Murphy. 1992. Molecular cloning and characterization of the constitutive bovine aortic endothelial cell nitric oxide synthase. J. Clin. Invest. 90:2092-2096.

22. Awolesi, M.A., W.C. Sessa, and B.E. Sumpio. 1995. Cyclic strain upregulates nitric oxide synthase in cultured bovine aortic endothelial cells. J. Clin. Invest. 96:1449-1454

23. Zembowicz, A., J. Tang, and K.K. Wu. 1995. Transcriptional induction of endothelial nitric oxide synthase type III by lysophosphatidylcholine. J. Biol. Chem. 270:17006-17010.

24. Hirata, K., N. Miki, Y. Kuroda, T. Sakoda, S. Kawashima, and M. Yokoyama. 1995. Low concentration of oxidized low-density lipoprotein and lysophosphatidylcholine upregulate constitutive nitric oxide synthase mRNA expression in bovine aortic endothelial cells. Circ. Res. 76:958-962.

25. Ravichandran, L.V., and R.A. Johns. 1995. Up-regulation of endothelial nitric oxide synthase expression by cyclic guanosine $3^{\prime}, 5^{\prime}$-monophosphate. FEBS Lett. 374:295-298.

26. Sessa, W.C., K. Pritchard, N. Seyedi, J. Wang, and T.H. Hintze. 1994. Chronic exercise in dogs increases coronary vascular nitric oxide production and endothelial cell nitric oxide synthase gene expression. Circ. Res. 74:349-353.

27. Harrison, D.G., R.C. Venema, J.-F. Arnal, N. Inoue, Y. Ohara, H. Sayegh, and T.J. Murphy. 1995. The endothelial cell nitric oxide synthase. Is it really constitutively expressed? Agents Actions. 45:107-117.

28. Wilcox, J.N., R.R. Subramanian, C. Sundell, W.R. Tracey, J.S. Pollock, D.G. Harrison, and P.A. Marsden. 1997. Expression of multiple nitric oxide synthase isoforms in normal and atherosclerotic vessels. Arterioscler. Thromb. Vasc. Biol. In press.

29. Nakayama, T., M. Soma, Y. Takahashi, Y. Izumi, K. Kanmatsuse, and M. Esumi. 1997. Association analysis of CA repeat polymorphism of the endo- thelial nitric oxide synthase gene with essential hypertension in Japanese. Clin. Genet. 51:26-30.

30. Bonnardeaux, A., S. Nadaud, A. Charru, X. Jeunemaitre, P. Corvol, and F. Soubrier. 1995. Lack of evidence for linkage of the endothelial cell nitric oxide synthase gene to essential hypertension. Circulation. 91:96-102.

31. Bossaller, C., G.B. Habib, H. Yamamoto, C. Williams, S. Wells, and P.D. Henry. 1987. Impaired muscarinic endothelium dependent relaxation and cyclic guanosine $5^{\prime}$ monophosphate formation in atherosclerotic human coronary artery and rabbit aorta. J. Clin. Invest. 79:170-174.

32. Shimokawa, H., N.A. Flavahan, and P.M. Vanhoutte. 1991. Loss of endothelial pertussis toxin sensitive $\mathrm{G}$ protein function in atherosclerotic porcine coronary arteries. Circulation. 83:652-660.

33. Liao, J.K., and S.L. Clark. 1995. Regulation of G protein alpha(i2) subunit expression by oxidized low-density lipoprotein. J. Clin. Invest. 95:14571463

34. Tsutsui, M., H. Shimokawa, S. Tanaka, I. Kuwaoka, K. Hase, N. Nogami, K. Nakanishi, and S. Okamatsu. 1994. Endothelial Gi protein in human coronary arteries. Eur. Heart J. 15:1261-1266.

35. Corson, M., N. James, S. Latta, R. Nerem, B. Berk, and D. Harrison. 1996. Phosphorylation of endothelial nitric oxide synthase in response to fluid shear stress. Circ. Res. 79:984-991.

36. Venema, R.C., H.S. Sayegh, J.-F. Arnal, and D.G. Harrison. 1995. Role of the enzyme calmodulin-binding domain in membrane association and phospholipid inhibition of endothelial nitric oxide synthase. J. Biol. Chem. 270: 14705-14711.

37. Michel, T., and O. Feron. 1997. Nitric oxide synthases: which, where, how, and why? J. Clin. Invest. 100:2146-2152.

38. Pou, S., W.S. Pou, D.S. Bredt, S.H. Snyder, and G.M. Rosen. 1992. Generation of superoxide by purified brain nitric oxide synthase. J. Biol. Chem. 267: 24173-24176.

39. Kojima, S., S. Ona, I. Iizuka, T. Arai, H. Mori, and K. Kubota. 1995. Antioxidative activity of 5,6,7,8-tetrahydrobiopterin and its inhibitory effect on paraquat-induced cell toxicity in cultured rat hepatocytes. Free Rad. Res. 23 419-430.

40. Pieper, G.M. 1997. Acute amelioration of diabetic endothelial dysfunction with a derivative of the nitric oxide synthase cofactor, tetrahydrobiopterin. J. Cardiovasc. Pharmacol. 29:8-15.

41. Stroes, E., J. Kastelein, F. Cosentino, W. Erkelens, R. Wever, H. Koomans, T. Luscher, and T. Rabelink. 1997. Tetrahydrobiopterin restores endothelial function in hypercholesterolemia. J. Clin. Invest. 99:41-46.

42. Thomson, L., M. Trujillo, R. Telleri, and R. Radi. 1995. Kinetics of cytochrome $\mathrm{c} 2+$ oxidation by peroxynitrite: implications for superoxide measurements in nitric oxide-producing biological systems. Arch Biochem. Biophys. 319:491-497.

43. Minor, R.L.J., P.R. Myers, R.J. Guerra, J.N. Bates, and D.G. Harrison. 1990. Diet-induced atherosclerosis increases the release of nitrogen oxides from rabbit aorta. J. Clin. Invest. 86:2109-2116.

44. Mügge, A., J.H. Elwell, T.E. Peterson, T.G. Hofmeyer, D.D. Heistad and D.G. Harrison. 1991. Chronic treatment with polyethylene glycolated superoxide dismutase partially restores endothelium-dependent vascular relaxations in cholesterol-fed rabbits. Circ. Res. 69:1293-1300.

45. White, C.R., T.A. Brock, L.Y. Chang, J. Crapo, P. Briscoe, D. Ku, W.A Bradley, S.H. Gianturco, J. Gore, and B.A. Freeman. 1994. Superoxide and peroxynitrite in atherosclerosis. Proc. Natl. Acad. Sci. USA. 91:1044-1048.

46. Heitzer, T., H. Just, and T. Munzel. 1996. Antioxidant vitamin C improves endothelial dysfunction in chronic smokers. Circulation. 94:6-9.

47. Ting, H.H., F.K. Timimi, K. Boles, S. Creager, P. Ganz, and M.A. Creager. 1995. Vitamin C acutely improves endothelium-dependent vasodilation in patients with non-insulin-dependent diabetes mellitus. Circulation. 92(Suppl 1):1747. (Abstr.)

48. Solzbach, U., B. Hornig, M. Jeserich, and H. Just. 1997. Vitamin C improves endothelial dysfunction of epicardial coronary arteries in hypertensive patients. Circulation. 96:1513-1519.

49. Griendling, K., J.D. Ollerenshaw, C.A. Minieri, and R.W. Alexander 1994. Angiotensin II stimulates NADH and NADPH activity in cultured vascular smooth muscle cells. Circ. Res. 74:1141-1148.

50. Pagano, P., Y. Ito, K. Tornheim, P. Gallop, A. Tauber, and R. Cohen 1995. An NADPH oxidase superoxide-generating system in the rabbit aorta Am. J. Physiol. (Heart Circ. Physiol). 268:H2274-H2280.

51. Mohazzab, K.M., and M.S. Wolin. 1994. Sites of superoxide anion production detected by lucigenin in calf pulmonary artery smooth muscle. Am. J. Physiol. 267:L815-L822.

52. Mohazzab, K.M., P.M. Kaminski, and M.S. Wolin. 1994. NADH oxidoreductase is a major source of superoxide anion in bovine coronary artery endothelium. Am. J. Physiol. 266:H2568-H2572.

53. Clark, R.A., K.G. Leidal, D.W. Pearson, and W.M. Nauseef. 1987 NADPH oxidase of human neutrophils. Subcellular localization and characterization of an arachidonate-activatable superoxide-generating system. J. Biol. Chem. 262:4065-4074.

54. Amit, N., T.P. Huu, P. Sourbier, C. Marquetty, and J. Hakim. 1988. Role of cytochrome b-559 in arachidonic acid activation of resting human neutrophils. Biochim. Biophys. Acta. 944:437-443. 
55. Münzel, T., S. Kurz, S. Rajagopalan, W. Bennington, A. Thompson, B. Freeman, and D. Harrison. 1996. Hydralazine prevents nitroglycerin tolerance by inhibiting activation of a membrane-bound NADH oxidase: a new action for an old drug. J. Clin. Invest. 98:1465-1470.

56. Mohazzab, K.M., and M.S. Wolin. 1994. Properties of a superoxide anion-generating microsomal NADH oxidoreductase, a potential pulmonary artery PO2 sensor. Am. J. Physiol. 267:L823-L831.

57. Rajagopalan, S., S. Kurz, T. Münzel, M. Tarpey, B. Freeman, K. Griendling, and D. Harrison. 1996. Angiotensin II-mediated hypertension in the rat increases vascular superoxide production via membrane NADH/NADPH oxidase activation: contribution to alterations of vasomotor tone. J. Clin. Invest. 97:1916-1923.

58. Bech Laursen, J., S. Rajagopalan, M. Tarpey, B. Freeman, and D. Harrison. 1997. A role of superoxide in angiotensin II, but not catecholamine-induced hypertension. Circulation. 95:588-593.
59. Münzel, T., H. Sayegh, B.A. Freeman, M.M. Tarpey, and D.G. Harrison. 1995. Evidence for enhanced vascular superoxide anion production in nitrate tolerance. A novel mechanism underlying tolerance and cross-tolerance. J. Clin. Invest. 95:187-194.

60. Fukui, T., B. Lassegue, H. Kai, R.W. Alexander, and K.K. Griendling. 1995. Cytochrome b558 a-subunit cloning and expression in rat aortic smooth muscle cells. Biochim. Biophys. Acta. 1231:215-219.

61. Ushio-Fukai, M., A.M. Zafari, T. Fukui, N. Ishizaka, and K.K. Griendling. 1996. p22phox is a critical component of the superoxide-generating NADH/NADPH oxidase system and regulates angiotensin II-induced hypertrophy in vascular smooth muscle cells. J. Biol. Chem. 271:23317-23321.

62. Fukui, T., S. Rajagopalan, N. Ishizaka, Q. Capers, W. R Taylor, D.G. Harrison, H. de Leon, J.N. Wilcox, and K.K. Griendling. 1997. Cytochrome b558 $\alpha$-subunit mRNA expression and NADPH oxidase activity are increased in aortas from hypertensive rats. Circ. Res. 80:45-51. 